\title{
JOGO DE TABULEIRO DIGITAL COMO RECURSO DIDÁTICO NO ENSINO DE QUÍMICA
}

\author{
Apresentação: Pôster \\ Wellington da Silva Rodrigues ${ }^{1}$; Géssica Fernandes da Silva²; Mônica Dias de Souza \\ Almeida $^{3}$
}

\section{Introdução}

Atualmente vem sendo desenvolvidos trabalhos que abordam os jogos como um método eficaz para promover a aprendizagem dos alunos de maneira divertida e estimulante. $\mathrm{O}$ intuito é contornar o tipo das práticas docentes tradicionais, que além de serem exaustivas, contribuem principalmente, com as taxas de reprovação e evasão escolar e ainda com a simples memorização dos conteúdos. Na Química, ciência que possui conceitos abstratos e de difícil compreensão, essa prática tem levado os estudantes ao desinteresse o que interfere, sobretudo no processo de ensino e aprendizagem.

$\mathrm{Na}$ disciplina de Química, a maior parte dos conteúdos abordados exige a realização de diversos cálculos matemáticos para posterior interpretação dos resultados. Porém, as metodologias e práticas utilizadas pelos professores não têm favorecido a aprendizagem dos estudantes.

Aos Professores cabe o desafio de ajudar os alunos a superarem suas dificuldades, despertar neles o interesse pela ciência, conduzi-los a aprendizagem significativa e associar os conceitos vistos na disciplina com o cotidiano. Pensando nisso, criou-se um jogo como recurso didático, com o objetivo de ajudar os professores a inovarem suas práticas metodológicas e obterem êxito no processo ensino-aprendizagem. O mesmo aborda os conteúdos Tabela Periódica, Propriedades Periódicas e Aperiódicas dos elementos químicos e Diagrama de Linus Pauling. Ao aliar o jogo aos conceitos químicos espera-se que os alunos desenvolvam com mais facilidade os conteúdos abordados e sintam-se mais estimulados a participar e a aprender.

\section{Fundamentação Teórica}

A busca por novas metodologias e estratégias de ensino para a motivação da aprendizagem, que sejam acessíveis, modernas e de baixo custo, é sempre um desafio para os professores (Rosa e

\footnotetext{
${ }^{1}$ Graduando de Licenciatura em Química, IF Sertão PE, wellingtonsrq9@gmail.com

${ }^{2}$ Graduanda de Licenciatura em Química, IF Sertão PE, gessica.fernandes96@hotmail.com

${ }^{3}$ Professora do curso de Licenciatura em Química, IF Sertão PE, monica.dias@ifsertao-pe.edu.br
} 
Rossi, 2008; Brasil, 2006). Nessa direção, os jogos didáticos surgem como uma alternativa, pois incentivam o trabalho em equipe e a interação aluno-professor; auxiliam no desenvolvimento de raciocínio e habilidades; e facilitam o aprendizado de conceitos (Vygotsky, 1989).

O uso de jogos está descrito nos Parâmetros Curriculares Nacionais (PCN), pois desenvolve a capacidade afetiva e as relações interpessoais, permitindo ao aluno colocar-se no ponto de vista do outro, refletindo, assim, sobre os seus próprios pensamentos (Brasil, 1997). Desta forma, a utilização de jogos em sala de aula, tem se mostrado muito adequada como meio de motivação e melhora na relação ensino-aprendizagem no que diz respeito ao ensino de química, auxiliando ainda no desenvolvimento da lógica, criatividade, entre outros benefícios (Soares, 2008). Entretanto, o ensino de química praticado atualmente nas escolas ainda utiliza o processo de memorização.

Zanon, et al (2008) defendem que, para ser considerado educativo, um jogo deve apresentar objetivos pedagógicos claros. Para tanto, faz-se necessário que, em sua fase de planejamento, o jogo seja elaborado com o objetivo de atingir conteúdos específicos e desenvolver habilidades cognitivas, tais como criatividade, raciocínio rápido e resolução de problemas, indispensáveis para o processo de aprendizagem, possibilitando aos alunos uma melhor compreensão de conteúdos de difícil aprendizagem e podendo, portanto, ser utilizado para cumprir certos objetivos pedagógicos. Caso contrário, o jogo será considerado apenas um entretenimento.

De acordo com Cavalcanti e Soares (2010) a utilização do jogo didático pode atribuir sentidos a partir de uma atividade que envolve diversão, simulação do real e construção de significados. Além disso, os jogos também conferem ao professor um papel primordial no processo de desenvolvimento e crescimento intelectual dos alunos, uma vez que lhes conduz à construção do conhecimento a partir de novas descobertas, estimula nos alunos o interesse pela disciplina e pelo conhecimento e avalia a aprendizagem dos alunos.

\section{Metodologia}

$\mathrm{O}$ trabalho trata-se de uma pesquisa na área do ensino, com abordagem qualitativa. $\mathrm{O}$ mesmo foi aplicado em uma turma com 26 alunos de primeiro ano do Ensino Médio do Colégio Estadual Lomanto Júnior, localizado na cidade de Juazeiro-BA. É um colégio de porte médio que atende a alunos de classes média e baixa, oriundos de diferentes bairros da cidade. Para aplicação do jogo dividiu-se a sala em duas equipes.

O jogo foi desenvolvido no power point, utilizando-se de diversos recursos oferecidos pelo programa. Através do recurso "Hiperlink" foi possível desenvolver o jogo de modo que cada casa da trilha seja direcionada a outra página contendo duas perguntas que deverão ser respondidas pelos 
jogadores, com o objetivo de chegar ao final do percurso e vencer o jogo. O jogo é composto por um dado, a Trilha e uma ficha de acompanhamento para registros de questões respondidas, erros e acertos; além de folha de rascunho para resolução de questões. O dado é numerado de um a quatro, para indicar quantas casas os participantes devem andar, e também possui algumas ordens, como "retorne 2 casas", "avance 2 casas", para animar o jogo.

A trilha possui obstáculos pelos quais os participantes devem atravessar. Esses obstáculos são perguntas referentes a conteúdos químicos (Tabela Periódica, Propriedades Periódicas e Aperiódicas dos elementos e Diagrama de Linus Pauling). Em cada casa da trilha existem duas perguntas. Cada pergunta possui quatro alternativas e somente uma delas é correta. Esta, por sua vez, está "hiperlincada" para a página Parabéns. O propósito de hiperlincar a resposta correta para esta página é o de garantir que a dinâmica do jogo não seja interrompida, ou seja, quando uma determinada pergunta, lida pelo jogador ou pelo mediador do jogo seja respondida, o aluno que a respondeu e todos os demais participantes do jogo terá conhecimento imediato do erro ou do acerto. $\mathrm{Na}$ trilha existem também curiosidades sobre alguns dos elementos químicos que deverão ser explicadas pelo mediador do jogo e, consequentemente, a equipe deverá lançar o dado novamente, dando sequencia ao jogo.

\section{Resultados e Discussões}

No início da aplicação do jogo de tabuleiro foi possível perceber que alguns alunos no princípio, achava que o jogo seria apenas uma brincadeira sem levar em consideração o conteúdo, alguns não mostravam interesse em jogar e outros se mostravam tímidos. Porém, quando foram expostas as regras e ao começarem a jogar, os alunos foram se soltando e se interessando, aqueles que não queriam brincar, já estavam empolgados e participativos.

Como já foi dito, a turma foi dividida em dois grupos de treze alunos, os mesmos eram responsáveis por lançar o dado e responder as perguntas indicadas de acordo com o lançamento do dado. Com a sequência do jogo, quando os alunos estavam localizados nas casas das perguntas, os mesmos se mostravam atenciosos para escutar e entender a pergunta, para acertarem a resposta e quando acertavam ficavam eufóricos, pois não queriam de maneira alguma errar e nem perder no jogo. Soares (2008) descreve que essa motivação favorece a descontração, a participação e a empolgação dos jogadores, possibilitando que aconteça uma competição divertida, auxiliando assim na aprendizagem.

Outra questão importante a ser levantada é a interação entre os alunos que ocorriam durante o jogo, os mesmos depois de lerem as informações e de responderem as perguntas, debatiam sobre o 
assunto e exponham suas opiniões e ideias. Sucedia no andamento do jogo, a troca de conhecimentos. Outro fato relevante a ser exposto é a liberdade de expressão ocasionada no aluno, na qual surge por meio das interações aluno-aluno e aluno-professor, devido ao simples ato de jogar e participar.

Após toda a análise do recurso, verificamos que o jogo constrói novas descobertas, enriquece o conhecimento e modifica o papel do professor que passa a ser um mediador do ensino aprendizagem, o aluno passa a participar mais da aula enquanto o professor fornece estímulo aos alunos para construir seu conhecimento a respeito de determinado conteúdo. Assim, a inovação e a mudança na prática didática, juntamente com métodos que proporcionam a contextualização, favorecem a participação, a motivação e a formação do aluno.

Segundo relato dos alunos houve maior facilidade da compreensão do conteúdo diante da aplicação do jogo em relação a explicação apenas de forma teórica. Verificou-se, portanto, a necessidade da implementação de diferentes formas de aprendizagem para atrair a atenção dos alunos, proporcionando um maior interesse no conhecimento da tabela periódica, instigando sua curiosidade e facilitando o processo de ensino. O trabalho em grupo favoreceu uma maior integração entre os alunos, prevalecendo um clima de cooperação no sentido de somar os conhecimentos e esforços, com o intuito de vencer o jogo, criando um clima adequado para a investigação e a busca de soluções para as questões.

Por fim, devemos expor e ressaltar que houve no início do jogo certa euforia e agitação nos alunos, sendo isso considerado normal, pois se tratando de um método diferente do que eles estão acostumados no seu dia a dia na sala de aula, favoreceu e ocorreu o entusiasmo e a motivação da turma. Porém, compete ao professor à função de esclarecer as regras, de informar o conteúdo e de revelar qual será o objetivo do jogo. Desta maneira, o fato de realizar a atividade de forma organizada, apontando o objetivo do jogo, definindo e esclarecendo as regras e ressaltando a importância de segui-las, consegue-se que a atividade fique organizada.

\section{Conclusões}

No ensino de química, os jogos tendem a ganhar espaço cada vez mais, sendo necessário que a utilização desse recurso seja pensada e planejada dentro de uma proposta pedagógica mais consistente. É indispensável que os professores reconheçam o real significado da educação lúdica para que possam aplicar os jogos adequadamente em suas aulas.

A aplicação da atividade na escola foi bem-sucedida, tanto no aspecto conceitual como no que diz respeito a despertar o interesse e manter o aluno focado durante a atividade. Com o jogo foi 
possível abordar à importância do conhecimento da tabela periódica, motivando assim maior interesse pela disciplina de química. Além de possibilitar uma maior interação entre os alunos, o jogo contribuiu para a socialização e negociação de significados dentro dos grupos e o professor pôde atuar como mediador levantando questionamentos e levando a reflexão, contribuindo assim com a efetivação e potencialização do processo ensino-aprendizagem de forma atrativa e estimulante.

\section{Referências}

BRASIL. Ministério da Educação. Secretaria de Educação Média e Tecnológica. Parâmetros curriculares nacionais, Brasília: MEC, SEMTEC, 1997.

BRASIL. Ministério da Educação. Secretaria de Educação Média e Tecnológica. PCN+ Ensino Médio: orientações educacionais complementares aos Parâmetros Curriculares Nacionais Ciências da Natureza, Matemática e suas Tecnologias. Brasília: MEC; SEMTEC, 2006.

CAVALCANTI, E. L. D. e SOARES, M. H. F. B. O ludismo e avaliação da aprendizagem: possibilidades para o ensino de química. In: ENCONTRO NACIONAL DE ENSINO DE QUÍMICA, 15, 2010. Brasília. Anais... Brasília: UnB, 2010, p. 03-04.

ROSA, M. I. P. e ROSSI, A. V. Educação Química no Brasil: memórias, políticas e tendências. Campinas: Átomo, 2008, p. 15-38.

SOARES, M. Jogos para o Ensino de Química: teoria, métodos e aplicações. Espírito Santo: Ex Libris, 2008, p. 01-02.

VYGOTSKY, L.S. A formação social da mente. São Paulo: Martins Fontes, 1989, p. 31-37.

ZANON, D. A.V; GERREIRO, M. A.S; OLIVEIRA, R. C. Jogo Didático Ludo Químico para o ensino de nomenclatura dos compostos orgânicos: projetos, produção, aplicação e avaliação. Ciências \& amp; Cognição. Vol 13 (1): 72-81, 2008. 